\title{
Impact Of Human Factors On The Labour Process: A Case Study
}

Prakash Singh, Nelson Mandela Metropolitan University, South Africa Thembinkosi Twalo, Human Sciences Research Council, South Africa

\begin{abstract}
The sustainability of the Buffalo City Metropolitan Municipality (BCMM) in South Africa is being threatened by the reported cases of poor administration, weak management of resources, inappropriate job performance, and inappropriate job behaviour of some of its employees. Since the structural-functionalists assume that formal education is a solution to societal challenges, it therefore means that the BCMM should not be experiencing this threat since many of its workers have various levels of formal education. Consequently, this case study using the mixed method research approach set out to investigate the paradoxical co-existence of inappropriate job behaviour and performance with formal education at the BCMM. It moved from the premise that labour (ability to work) is a product of multifarious forms of capital and thus amalgamated four forms of capital - human, social, cultural, and reputation-into a theoretical framework in order to get a broader explanation of the employees' job behaviour and performance. This made it possible for job behaviour and performance to be investigated from multiple perspectives, as opposed to the dominant human capital model that predominantly uses schooling to explain the workers' performance. This drew attention to the view that the labour process does not take place in a vacuum, but in a particular context that is shaped by several imperatives and it involves humans with particular motives, will, attitudes, ethics, and values. Hence, this exploratory case study demonstrates how the sustainability of the BCMM is undermined by different factors that are human in nature.
\end{abstract}

Keywords: Labour Process; Resource Management; Job Performance; Job Behaviour

\section{INTRODUCTION}

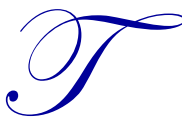

his study acknowledged that labour (ability to work) is a product of multifarious forms of capital; hence, it amalgamated four forms of capital - human, social, cultural, and reputation- into a theoretical framework in order to get a broader explanation of the workers' job behaviour and performance. The multifarious forms of capital contribute to the formation of skill; hence, the notion of broad skills. Therefore, how workers discharge their responsibilities is determined by multifarious factors such as cultural capital (the workers' family background, race, ethnicity, personality, and geographical area) (Bourdieu, 1977), reputation capital (the workers' brand, public perceptions of trustworthiness, popularity, authority in the field, ethics, integrity, and reputation) (Ingbretsen, 2011), social capital (the workers' social development, social relations, and social networks) (Blackmore, 1997), and human capital (schooling) (Becker, 1975). The value of adopting the broad skills approach lies in gaining a broader perspective on job performance as opposed to the dominant use of the human capital model alone which uses schooling as the centre of the explanation of job performance. In practice, the human capital model is, inter alia, characterised by its association of job performance problems with lack of skills. This study draws attention to the role of attitudes, ethics, and values in the labour process as these also contribute to job performance problems. In fact, the adoption of multiple perspectives for investigating the paradoxical co-existence of inappropriate job behaviour and performance with formal education explored several factors that enable this phenomenon, besides the lack of skills. Such factors include the job environment, ineffective performance management system, compromised municipal effectiveness and efficiency due to the politicisation of municipal management and manipulation of the labour process to suit the interests of the workers who want to engage in inappropriate practices. 
In 2011, the BCMM was awarded category-A, or metropolitan municipality status, which means it started acting as both a local municipality and a district municipality in terms of its responsibilities. The BCMM's ability to cope with its responsibilities has been called into question by various reports of poor administration, weak management of resources, such as finances, human, and assets, inappropriate job performance, and inappropriate job behaviour of some of the workers (Nombembe, 2013; Nombembe, 2011; Coetzer, 2009; Times Live, 2011). Such reports are regularly made in the media and further evidence is available from various sources like audit reports, parliamentary discussions, reports to parliament, municipal reports, and departmental reports. The structuralfunctionalist school of thought perceives formal education as one of the factors that curb inappropriate job behaviour and performance in an effort to achieve stability and consensus in society (Bryant, 2012; Guerrero, 2005; Haralambos \& Heald, 1985; Moore \& Moore, 1982; Almquist, Chafetz, Chance, \& Corder-Bolz, 1978). Paradoxically, the inappropriate job behaviour and performance practices have been taking place at national, provincial, and local level of government, despite the fact that many BCMM workers have formal education. Since BCMM workers have varying levels of formal education, yet inappropriate job behaviour and performance continue to be reported, this study seeks to establish how the two co-exist; that is, formal education and inappropriate job behaviour and performance.

This study hypothesised that the continued co-existence of skills with inappropriate job behaviour and performance is indicative of management gaps at the BCMM. In order to close the gaps significantly that enable perpetuation of inappropriate job behaviour and performance, the application of broad skills, together with effective management practices, is required. The co-existence of formal education with such behaviour and performance is made possible by the "[k]now the rules well, so you can break them effectively" principle (Dalai Lama, 2013, p. 2). The role that effective management could play in this regard is to identify, address and prevent broken rules for the optimum performance of the BCMM as a case study.

\section{Evidence of Threat to the Sustainability of the BCMM}

Economic growth and service delivery in local government often get compromised because this tier of government administration is generally known to have conspicuous skills shortage, poor governance, financial mismanagement, and maladministration (Department of Cooperative Governance and Traditional Affairs (COGTA), 2010; Stokes, 2010; Coetzer, 2009). At the BCMM, several cases of inappropriate job behaviour and performance have been reported and they show that this municipality is experiencing financial mismanagement, lack of service delivery, fraud, and corruption (Mawonga, 2012; Benya Nqolase, 2011). These practices threaten the sustainability of the municipality, especially when the culprits are determined to continue with them.

The Auditor General revealed that the BCMM has never received a clean audit from his office because, since the 2002/03 financial year, it received many qualified audit opinions, disclaimer and adverse audit reports and regressed further to an adverse opinion in the 2010/11 financial year (Nini, 2012a; Nini, 2012b). The adverse audit opinion is worse than a disclaimed opinion as it means the Auditor General believes the financial statements of the municipality contained false information or that some facts were left out (de Kock, 2012). In fact, the Auditor General rated the BCMM as the worst metropolitan council in the 2010/11 audit (Times Live, 2012). This is a clear indication of regression in the municipality because in 2003, "it was voted the best municipality in South Africa" (Mabindla, 2003, p. 1). Van Onselen (2012) in Table 1 gives a broader view of the BCMM's performance since 2002/03 and it shows that the BCMM has been struggling for a while with regard to its financial management.

Table 1: BCMM Audit Outcomes 2002-2011

\begin{tabular}{|c|c|}
\hline \multicolumn{1}{|c|}{ Year } & Outcome \\
\hline $2002 / 03$ & Qualified \\
\hline $2003 / 04$ & Financially unqualified \\
\hline $2004 / 05$ & Qualified \\
\hline $2005 / 06$ & Adverse \\
\hline $2006 / 07$ & Qualified \\
\hline $2007 / 08$ & Qualified \\
\hline $2008 / 09$ & Qualified \\
\hline $2009 / 10$ & Disclaimer \\
\hline $2010 / 11$ & Adverse \\
\hline
\end{tabular}

Source: Van Onselen (2012) 
Table 1 reveals that since 2002/03, the BCMM has never had a clean or unqualified audit opinion. This is rather concerning in light of its responsibilities and the need to be financially sustainable. Furthermore, Ratings Africa (2011) calculates the Municipal Financial Stability Index (MFSI) and gives the rating of the eight metropolitan municipalities, among all the South African municipalities, in descending order of sustainability. From this, we learn that Cape Town ranked 63, Buffalo City 59, eThekwini 53, Ekurhuleni 47, Manguang 43, Nelson Mandela Bay 36, Tshwane 32, and Johannesburg 26 (Badenhorst, 2012). Although the BCMM financial stability ranking stands at 59, which is better than many other metros, the MFSI 2011 also gives a four-year (2007-2010) trend of the BCMM financial stability which shows that it is on a significant decline (Ratings Africa, 2011).

\section{DYNAMICS OF THE LABOUR PROCESS}

The uncritical acceptance of formal education, as a panacea to socio-economic challenges, tends to translate to a failure to critically analyse the skills required to undertake a particular task. Skills acquired through formal education are narrow in nature as they predominantly enhance job-specific capabilities and, to a lesser extent, enhance other crucial elements that contribute to quality work performance, such as ethics, values and attitudes. Similarly, skills acquired through socialisation or background are also narrow in nature as they predominantly enhance particular forms of behaviour such as interpersonal skills, communication, responsibility, integrity, empathy, teamwork, and sociability. However, the recognition of the various forms of narrow skills acquired through schooling, socialisation, culture, background and otherwise, translates to the notion of broad skills. The notion of broad skills reflects that labour (ability to do a job) is a product of multifarious elements and is determined by the totality of a human being.

The importance of taking into consideration the totality of a human being when workers discharge their responsibilities was further echoed by the Auditor General, Terence Nombembe (2012a), on the occasion of the 2010/11 municipal audit report, which revealed that none of the South African metropolitan municipalities received a clean audit. Nombembe argued that such audit reports in the metropolitan municipalities are disappointing since metropolitan municipalities have more capacity than smaller municipalities. He then inferred that in the case of metropolitan municipalities, such poor audit reports are due to, inter alia, lack of discipline, lack of commitment, lack of consequences for poor performance, and lack of a culture of accountability.

Maudlen, Bentley, Dwyer, and Houston's (2004) notion of errors of commission relates to Nombembe's assessment that mismanagement is not only due to shortage of skills, but that there are attitudinal and misconduct factors as well. If, as Nombembe considers, some accountants report just to meet the minimum annual requirements, this cannot be attributed to lack of skills, but rather to a lack of the appropriate attitude, diligence, and integrity. Since the teaching of these aptitudes is not the key purpose of schooling, though they are vital components of labour (the ability to do a job), it means that it should not be assumed during recruitment and performance appraisals that recruits or workers have them. Recruitment and performance appraisals, however, are summative stages where the panel seeks to establish if applicants or incumbents are able to undertake their responsibilities satisfactorily. Before broad skills can be assessed, they need to be inculcated through teaching, influence, and socialisation. It is apparent that the use of one medium (an oral or written examination) to ascertain the extent to which broad skills have been inculcated is insufficient because the errors of commission that Maudlen et al. (2004) refer to cannot be established through examinations. Furthermore, in Figure 1, McShane and Von Glinow (2009, p. 34) show that job performance determinants are multi-dimensional. They involve organisational, group and individual mechanisms, and individual characteristics. This tends to subvert the positivist assumption, captured by Chansarn (2010), who argues that "only education and technological progress are the significant determinants of the growth rate of labor productivity" (p. 1). 


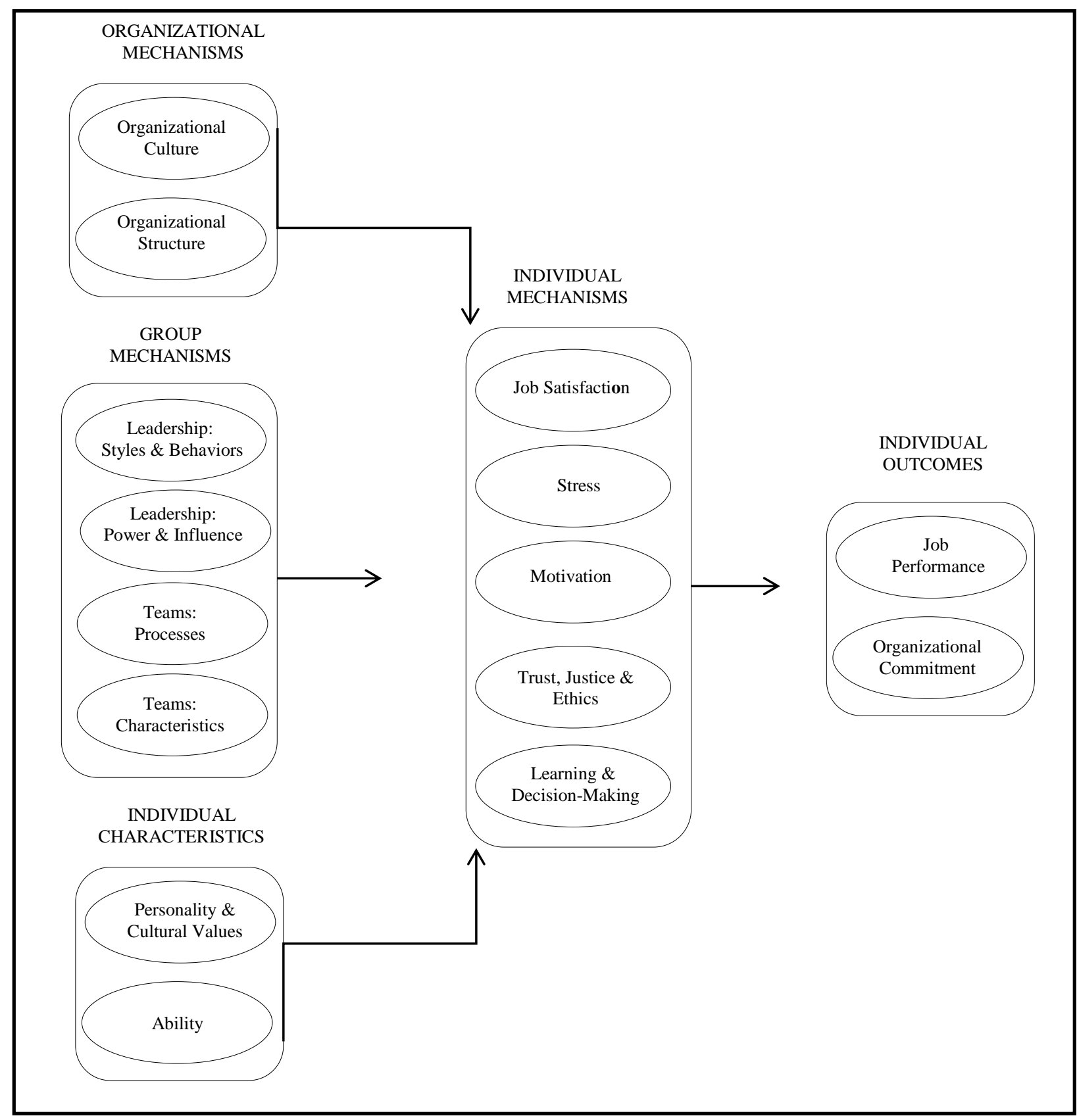

Figure 1: Multi-Dimensional Determinants of Job Performance

Source: McShane \& Von Glinow, 2009

McShane and Von Glinow's (2009) diagram shows that organisational, group and individual mechanisms, and individual characteristics, collectively determine job performance. Westover (2011) concurs, adding that job satisfaction, together with other positive attributes such as life satisfaction, organisational commitment, and worker health, are important determinants of job performance. Table 1 reflects the important outcomes of job satisfaction as depicted by Westover (2011), buttressing the notion that appropriate job performance is an outcome of numerous and varied factors. 


\section{METHODOLOGY}

This case study used the mixed method approach; that is, a combination of qualitative and quantitative methods (Creswell \& Plano-Clark, 2007). The investigation merited a mixed methods approach because of the complexity of the notion of broad skills, some of whose components are immeasurable, unobservable, and unquantifiable. Mixing the qualitative and quantitative data helped to provide a better understanding of the municipal workers' job behaviour and performance at the BCMM since limited data would have been collected if either method had been used. Qualitative methods included an analysis of relevant literature, semi-structured interviews with sampled workers from various departments and in different ranks. The quantitative method was in the form of a questionnaire with 79 closed-ended questions of which 10 were biographical. The questionnaire also included six qualitative questions, thus the total number of questions was 85. BCMM workers were requested to complete and return the questionnaire that was sent to them by email and fax, and, later, hand delivered.

As of 30 June, 2012, the BCMM had eight directorates, 39 departments and a total staff complement of 5,427 (Buffalo City Metropolitan Municipality, 2012). Ten respondents per department were meant to be sampled for responding to the questionnaire so as to have 390 respondents in total. For the structured interviews, one person was meant to be sampled per directorate so as to have eight interviewees in total. However, due to fieldwork logistics that included a high rate of refusal to participate in some departments, the share of respondents per department could not be balanced. Consequently, some departments were over-represented and others were underrepresented. In lieu of getting 398 respondents ( $7 \%$ of the total staff complement), only 342 (6\% of the total staff complement) could participate. However, physically administering the questionnaire around the BCMM offices meant that the respondents were much more than 342 . This is because the researcher had to explain to the workers what the questionnaire was about and, in return, they spoke about their experiences and observations at the BCMM, including those who refused to complete the questionnaire. The refusal to complete the questionnaire was on account of lack of time by some workers, fear of victimisation because the environment was highly political, and research fatigue by those who felt that they had participated in too many research projects, yet nothing seemed to change.

All questions in the questionnaire and interview were formulated in such a way that they adhere to the study's conceptual framework, the amalgamation of human, social, cultural, and reputation. Purposeful sampling was made since special attention had to be paid to staff with formal education in order to investigate the co-existence of formal education with inappropriate job behaviour and performance. However, many workers (49\%) had not passed grade twelve and most of them were in elementary occupations (Buffalo City Metropolitan Municipality, 2011), so the formal education prerequisite of the participants had to take this into consideration. The level of formal education was not made a prerequisite because most workers' education level was commensurate with their occupations. Taking these technicalities into consideration, the research questions then sought to probe how inappropriate job behaviour and performance persisted in the respective occupations despite the commensurate education credentials.

The research process and instruments were designed to enable meaningful analysis of the data because, on its own, data are meaningless unless systematically and logically interpreted. This interpretation was done through analysis of the responses against relevant laws and policies, such as the Local Government Municipal Structures Act (1998), Local Government Municipal Systems Act (2000), BCMM supply chain management (SCM) policy, and recruitment policy. For the quantitative data analysis, empirical statistical data were generated and processed by a qualified statistician from the Nelson Mandela Metropolitan University's (NMMU's) Statistics Department. Nonparametric statistical tests were conducted using SPSS version 12.0 programmes to analyse the relationships between variables. The Spearman rank correlation coefficient was used to determine the relationship between categorical variables. Non-parametric statistical methods are also called parameter-free or distribution-free methods because they rely on classification, ranking or order rather than numbers because the researcher is not in a position to give a numerical description of the population (Business Dictionary, 2013; Investopedia, 2013).

The statistical significance of the variables' correlation was calculated using the chi-square test and crosstabulations of the data. For each cross-tabulation, the chi-square test is reported which indicates statistical significance. Cramer's V is also reported, which indicates practical significance (small, medium, or large), and, 
lastly, Spearman rank correlation is also reported since the variables are ordinal. Since the instruments sought to determine the opinions of the respondents, ordinal scales were used since they are "measures of non-numeric concepts, like satisfaction, happiness, discomfort, etc." (My Market Research Methods, 2012, p. 1). For measuring the internal consistency (reliability) of the instrument, Cronbach's alpha was used. The levels of reliability appeared to be high with an average of 0.75 for employees' job behaviour and an average of 0.82 for employees' job performance.

Participation in this study was voluntary and all participants were made aware of this through the cover letter. Their confidentiality was also promised with the cover letter undertaking that participants' personal details would not be disclosed under any circumstances. There would therefore be no risk of harm, embarrassment, or offence to any participant or to the municipality. In fact, the biographical information section enabled them to remain anonymous since the required information was about their directorates and departments, type of employment, tenure, and educational qualifications. The cover letter also noted that there were no risks or discomforts associated with participation. It also clearly stated that there were no pecuniary benefits in participation to the participants, although the study would be very helpful in supporting policy changes that would help in addressing the broad skills shortage challenge. Participants' attention was also drawn to the fact that this research was approved by the NMMU's Research Ethics Committee, with ethics approval number H12-EDU-ERE-028. They were assured that this committee is competent, being composed of experts whose responsibility includes ensuring that the rights and welfare of participants in this study are protected and that the study is conducted in an ethical way.

\section{DISCUSSION OF FINDINGS}

\section{Determinants of Employment at the BCMM}

The fact that $64 \%$ of the respondents were of the view that many people get employed in the BCMM because of who they know, rather than what they know, shows the significant role played by social capital in BCMM employment. Table 2 shows the extent to which different attributes contribute in getting people employed at the BCMM.

Table 2: Extent to Which Different Attributes Contribute in Getting People Employed at the BCMM

\begin{tabular}{|c|c|c|c|c|c|c|c|c|c|}
\hline & 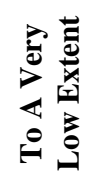 & 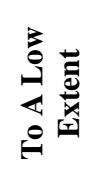 & 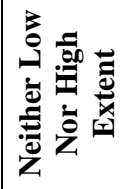 & 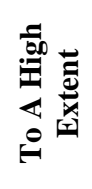 & 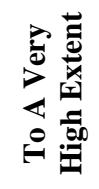 & 宸 & $\underset{\Sigma}{\tilde{E}}$ & 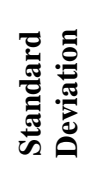 & 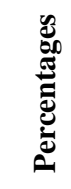 \\
\hline Educational Qualifications & 3.10 & 6.19 & 29.72 & 30.65 & 30.34 & 323 & 3.79 & 1.04 & $61 \%$ \\
\hline Gender & 5.92 & 5.30 & 35.20 & 51.71 & 1.87 & 321 & 3.38 & 0.86 & $54 \%$ \\
\hline Race & 6.27 & 27.59 & 30.09 & 30.41 & 5.64 & 319 & 3.02 & 1.03 & $35 \%$ \\
\hline Political Affiliation & 27.64 & 3.42 & 6.52 & 4.97 & 57.45 & 322 & 3.61 & 1.77 & $62 \%$ \\
\hline Physical Appearance & 55.45 & 29.60 & 10.59 & 2.18 & 2.18 & 321 & 1.66 & 0.91 & $4 \%$ \\
\hline
\end{tabular}

To get the percentages in Table 2, the last two options (to a high extent and to a very high extent) were combined, but the mean and standard deviation are for all five options in the Likert scale. The mean for the question on physical appearance is low (1.66) because the respondents tended to respond more on the low end of the scale, as confirmed by the frequency scores which show that the respondents chose to a very low extent (55.45) and to a low extent (29.60). Hence, only 4\% thought that people are employed at the BCMM on the basis of their physical appearance. Be that as it may, Table 2 shows that political affiliation plays a crucial role in determining one's chances of employment according to $62 \%$ of the respondents. Educational qualifications also play a crucial role according to $61 \%$ of the respondents. This is buttressed by the $68 \%$ of the respondents who thought that their qualifications were relevant to the kind of work they did on a daily basis. Few respondents (29\%) thought that their qualifications were not relevant to the kind of work they did on a daily basis. The cross-tabulation shows that, of the workers who thought that their qualifications were relevant to the kind of work they did on a daily basis, 52.07\% thought that people were employed in the BCMM because of their educational qualifications. This was established 
through a combination of respondents who agreed and strongly agreed on the question about their qualifications' relevance to the kind of work they did on a daily basis and those who chose the high extent and the very high extent on the question about whether people are employed in the BCMM on the basis of their educational qualifications. The relationship between the two variables was found to be statistically significant $\left(\mathrm{Chi}^{2}=210.52, \mathrm{df}=12, \mathrm{p}=\right.$ 0.0000 ) with Cramér's $V=0.47$, which indicates that this finding is of large practical importance. However, the Spearman correlation coefficient (0.06) indicates that generally there was no correlation between the relevance of the respondents' qualifications and employment of BCMM staff on account of educational qualifications. This buttresses the notion that although educational qualifications are known to be important for employment, in reality, they are not the principal determinants of finding employment; political affiliation is.

Political affiliation is evidently important and the effect of such social capital on employment and promotion goes a long way. For instance, nepotism has been a thorny issue in the BCMM for a while and for this reason, the South African Municipal Workers Union (SAMWU) protested outside the city hall on 28 September, 2012. One of its demands was that the municipality must investigate nepotism within the system and bring to book all those who are found guilty (Mxengi, 2012). It appeared from the interviews that nepotism had serious effects on job performance because workers who got their jobs or promotion through it, also got protected by their sponsors. This is depicted in Figure 2.

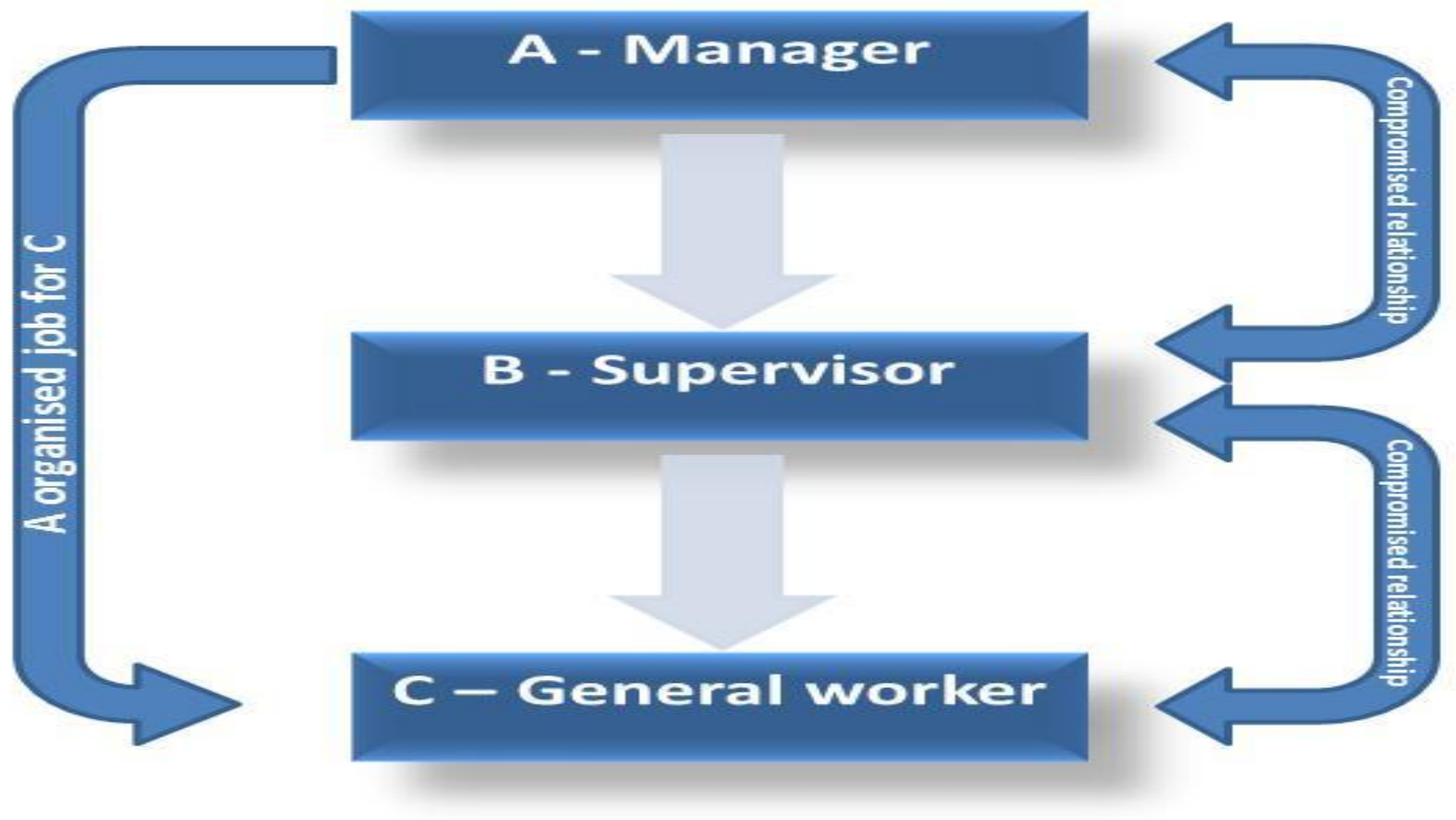

Figure 2: Compounding Effect of Nepotism on Job Performance

In the Figure 2 scenario, $\mathrm{A}$, who is a manager, organised a job for $\mathrm{C}$, who is a general worker. $\mathrm{C}$ reports to $\mathrm{B}$, who is her supervisor and line manager. B's line manager is A. It happened that $\mathrm{B}$ charged $\mathrm{C}$ for underperformance and $\mathrm{C}$ reported the matter to A. In protecting C, A victimised B for charging C. B was then forced to ignore C's underperformance in order to avoid victimisation from A. Consequently, inefficiency, and low productivity continued and this is how nepotism and favouritism creates tolerance for inappropriate job behaviour and performance at the BCMM.

Furthermore, some respondents advised that for many administrative positions, the appointment process appeared to comply with fair labour practices because the positions are advertised and candidates are shortlisted, interviewed, and eventually appointed. However, some members of the selection committee follow their political parties' instructions to appoint certain people which is easy to do since "in any recruitment panel sit three councillors and two (municipal) officials. As a result, the councillors always overrule the officials. Sometimes 
people who are not qualified or are inexperienced get appointed because they are friends with the politicians" (Loggi, 2009, p. 2). A similar concern was raised by the Auditor-General, Terence Nombembe (2012b), in the General Report on the Audit Outcomes of Local Government EASTERN CAPE 2011-12, wherein he noticed that "interference and nepotism by councillors in the recruitment processes often resulted in potential candidates with the required competencies not being shortlisted, resulting in unnecessary delays in the appointment of key personnel" (p. 114). Clearly, politicians influence the selection committee to select the party's preferred candidate regardless of who may have been more competent among the interviewees. The failure to select the party's preferred candidate has serious consequences for the party members, since they get threatened with removal from office. Similarly to the Figure 1 scenario, in order to avoid victimisation from the political party, the members then have to tow the line and see to it that the political party interests are served.

The political party instructions for the appointment of certain individuals are often given from different levels (national, provincial, and local). The respondents averred that this mode of operation - getting instructions from elsewhere - also applies in the issuing of tenders. Like the recruitment process, the tender process may appear to comply with fair procurement practices as the tenders are advertised, evaluated, and awarded. However, some members of the bid committee follow their political parties' instructions to give certain tenders to specific companies. The political party instructions from national or provincial level for the issuing of tender projects sometimes presents management and supervision challenges at the local level. This is because the expectation is that the municipality would monitor and supervise the projects, yet workers in such projects sometimes resist monitoring and supervision from the local leadership on the basis that the project is from a provincial or national level and it is such who need to do monitoring and supervision. Eventually, this translates to lack of clarity about reporting lines, lack of accountability and poor service delivery. This could explain the observation of $35 \%$ of the respondents who were of the view that people were not held accountable for the quality of work they produced while only $14 \%$ observed that they were held accountable and $51 \%$ either thought they were held accountable or not. The getting off the hook by workers with inappropriate job performance, as confirmed by $35 \%$ of the respondents, echoes the Auditor-General's (Terence Nombembe's, 2012a) assertion that in metropolitan municipalities, poor audit reports are due to, inter alia, lack of discipline, lack of consequences for poor performance, and lack of a culture of accountability.

\section{Human Factors' Impact on the Sustainability of the BCMM}

In light of the impact of human factors in the labour process, this study draws attention to the divergent objectives of the skill and the skill bearer because the application of knowledge is subject to the knowledge bearer's motives, will, attitudes, ethics, and values. Consequently, inappropriate job behaviour and performance practices at the workplace could be due to multifarious factors such as lack of the necessary capabilities or refusal to apply what has been learnt due to some prejudices such as racial prejudices, as in the case of those who refused to serve black clients (Breytenbach, 2009). Many respondents, for instance, thought that greed played a significant role in the inappropriate job behaviour of some BCMM workers. This is the serious omission made by the human capital theory since it regards schooling as the only contributing factor to labour (ability to do a job). It is for this reason that this study's theoretical framework was an amalgamation of the four theories - human, social, cultural, and reputation - in an effort to have a broader view of the factors that shape job behaviour and performance. Since it has been established that human nature plays a crucial role in how workers undertake their responsibilities, it is then important that this be taken into consideration in the BCMM's performance management system (PMS) and monitoring and evaluation of the workers' job performance.

Although most respondents thought that their qualifications were relevant to the kind of work they did on a daily basis, most respondents (59\%) were of the view that workers did not seem to care about the moral implications of their actions at work and $88 \%$ observed that some workers knew what was right, but still did what was wrong. The cross-tabulation shows that, of the respondents who thought BCMM workers did not seem to care about the moral implications of their actions at work, 57.09\% thought that some BCMM workers knew what was right but still did what was wrong. The relationship between the two variables was found to be statistically significant $\left(\mathrm{Chi}^{2}=\right.$ 250.25 , df $=16, \mathrm{p}=0.0000$ ) with Cramér's $\mathrm{V}=0.44$, which indicates that this finding is of large practical importance. However, the Spearman correlation coefficient (0.02) indicates that generally there was no correlation between the workers' taking into consideration of the moral implications of their actions at work and the workers' 
doing of what was wrong when they knew what was right. The workers' display of inappropriate behaviour when they knew what was right underscores the contradiction between education and practice. It shows that some workers, regardless of their formal education qualifications, practised inappropriate job behaviour and performance. The challenge, however, is that it is not known how many of those with formal education still practised inappropriate job behaviour and performance. Therefore, it is not possible to conclude that those who claimed to have relevant qualifications were also part of those who practised inappropriate job behaviour and performance. However, in light of the high numbers of those who observed that some workers knew what was right but still did what was wrong, it means that there is a greater probability that those with relevant educational qualifications were also part of those who practised inappropriate job behaviour and performance at the BCMM. This sheds some light on the paradoxical co-existence of formal education with inappropriate job behaviour and performance because the fact that some workers knew what was right, but still did what was wrong, is indicative of the paucity of appropriate attitudes, ethics and values. It also underscores the role of the human nature in the labour process because it plays a critical role in shaping the workers' job behaviour and performance. Therefore, the school of thought that attributes societal challenges such as poor service delivery, negligence, maladministration, and poor financial management to lack of skills (Kaseke, 2011; Stokes, 2010) needs to reconsider its stance, as some of these factors are not attributable to lack of capacity, but intention due to personal interests.

Section 195 (1) of the South African Constitution fosters "a high standard of professional ethics" (South African Local Government Association (SALGA) 2011, p. 10). In light of the significant number of respondents who were of the view that workers did not seem to care about the moral implications of their actions at work, 39\% of the respondents were of the view that what was important when working was how the job was done and not just the results and 33\% thought the results were more important than how the job is done, while $28 \%$ had no opinion in this regard. The cross-tabulation shows that, of the respondents who thought BCMM workers do not seem to care about the moral implications of their actions at work, 26.49\% thought that what was important when working were the results and not how the job was done. The relationship between the two variables was found to be statistically significant $\left(\mathrm{Chi}^{2}=342.28, \mathrm{df}=16, \mathrm{p}=0.0000\right)$ with Cramér's $\mathrm{V}=0.52$, which indicates that this finding is of large practical importance. The Spearman correlation coefficient (0.48) indicates that there was a moderate correlation between the workers' taking into consideration of the moral implications of their actions at work and the workers' thinking that what was important when working were the results and not how the job was done. The placing of more importance on how the job was done than the results is indicative of the 'tick a box' attitude and a mindless compliance with rules rather than taking full responsibility for one's work. This corroborates this study's hypothesis that the perpetual inappropriate job behaviour and performance at the BCMM is due to the paucity of broad skills, which includes various forms of knowledge, ethics, values, and attitudes. Although many BCMM workers had the required academic qualifications for their jobs, many did not seem to have the required ethics, values, and attitudes.

Not having the required ethics, values, and attitudes could be on account of not having learnt them or their erosion due to various circumstances. Awareness of injustice, inconvenience, and unfairness caused at the workplace could contribute toward the erosion of these components of broad skills or failure to apply them even if they are not eroded. Table 3 shows that different factors could play a role in compromising the job performance and behaviour of the workers and they are personal, systematic, and structural in nature.

To get the percentages in Table 3, the last two options (to a high extent and to a very high extent) were combined, but the mean, standard deviation, Cronbach alpha, and average inter-item correlation are for all five options in the Likert scale. The mean in Table 3 suggests that many respondents tended to choose the high end of the scale as the lowest average is 2.75 and the highest is 3.85 . Table 3 shows that according to $63 \%$ of the respondents, job behaviour that is against BCMM interests is mostly caused by lack of security for BCMM assets, greed (61\% of the respondents), and protection from relatives and friends for those accused of job misbehaviour, such as fraud and corruption (58\% of the respondents). The fact that lack of security for BCMM assets is ranked high among the factors that compromise the job performance and job behaviour of the workers is indicative of gaps in the BCMM systems that enable inappropriate job behaviour practices. Unclear job procedures were identified by $37 \%$ of the respondents as a contributing factor towards the workers' inappropriate job performance and behaviour. Section 53 (5) of the Local Government Municipal Systems Act 2000 seeks to ensure that the clarification of the roles and responsibilities of the respective role players make efficient and timeous governance possible (SALGA, 2011). Efficient and timeous governance at the BCMM seems to have been compromised by its internal procedures that 
negatively affect job performance according to $37 \%$ of the respondents. However, the majority (56\%) thought the internal procedures did not negatively affect job performance while $7 \%$ had no opinion on this matter.

Table 3: Extent to Which Different Attributes Compromise the Job Performance and Job Behaviour of the Workers

\begin{tabular}{|c|c|c|c|c|c|c|c|c|c|c|c|}
\hline 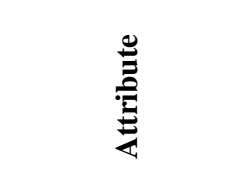 & 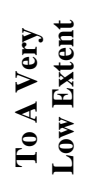 & 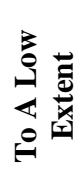 & 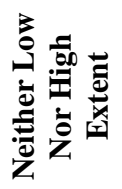 & 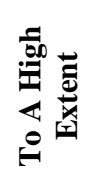 & 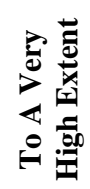 & 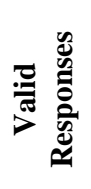 & $\sum_{\bar{\Sigma}}^{\tilde{E}}$ & $\begin{array}{l}\dot{\vec{U}} \\
\dot{0} \\
\dot{D}\end{array}$ & ن & 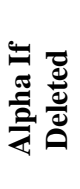 & 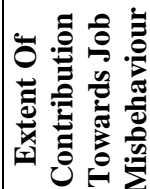 \\
\hline Ignorance & 7.67 & 28.12 & 52.40 & 5.43 & 6.39 & 313 & 2.75 & 0.91 & 0.37 & 0.69 & $12 \%$ \\
\hline Greed & 5.11 & 3.19 & 30.35 & 51.76 & 9.58 & 313 & 3.58 & 0.90 & 0.42 & 0.67 & $61 \%$ \\
\hline $\begin{array}{l}\text { Unclear job } \\
\text { procedures }\end{array}$ & 6.45 & 4.84 & 51.94 & 30.00 & 6.77 & 310 & 3.26 & 0.90 & 0.65 & 0.58 & $37 \%$ \\
\hline $\begin{array}{l}\text { Lack of security } \\
\text { for BCMM assets }\end{array}$ & 4.58 & 3.27 & 28.76 & 29.41 & 33.99 & 306 & 3.85 & 1.07 & 0.43 & 0.67 & $63 \%$ \\
\hline $\begin{array}{l}\text { Protection for } \\
\text { those accused of } \\
\text { job misbehaviour }\end{array}$ & 6.27 & 3.63 & 32.01 & 28.05 & 30.03 & 303 & 3.72 & 1.12 & 0.46 & 0.66 & $58 \%$ \\
\hline
\end{tabular}

The fact that only $12 \%$ of the respondents attribute job behaviour that is against BCMM interests to ignorance, shows that only a small share of inappropriate job behaviour and performance practices are erroneous due to ignorance and misunderstanding. Most of the inappropriate job behaviour and performance practices are purposeful with some level of understanding of the wrongfulness of the act and with the capacity to prevent or avoid it. That is why pumping more money toward skills development may not be an appropriate solution to this challenge, because some views in the skills development discourse suggest that there is capacity shortage; hence, the inappropriate job behaviour and performance challenge. On the contrary, when the inappropriate job behaviour and performance is purposeful, it means that the workers tend to use their capacity for wrongful ends in lieu of using it only for undertaking their occupational responsibilities. It also suggests that the workers are capable of doing their jobs but choose to pursue ulterior interests in line with the adage of knowing the rules well enough in order to know which one to break without being noticed. This suggests that human nature and work environment could be fueling the inappropriate job behaviour and performance challenge at the BCMM, hence Singh's (2011) cautionary note that "the human factor is not secondary" (p. 498) to the labour process.

\section{CONCLUSION}

Considering the impact of human factors in the labour process, this exploratory case study draws attention to the divergent objectives of skill and skill bearer, with the application of knowledge subject to the knowledge bearer's motives, will, attitudes, ethics, and values. Consequently, inappropriate job behaviour and performance practices could be due to numerous factors such as lack of the necessary capabilities or refusal to apply what has been learnt due to racial or other prejudices (Breytenbach, 2009). Many respondents in this study concurred that greed plays a significant role in inappropriate job behaviour by several BCMM employees. This is the serious omission of human capital theory, which regards schooling as the only factor contributing to the ability to do a job. For this reason, this study's theoretical framework was an amalgamation of the four theories - human, social, cultural, and reputation - in an effort to obtain a broader view of the factors that shape job behaviour and performance. Since it has been established that human nature plays a crucial role in how workers undertake their responsibilities, it is important that this be taken into consideration in the BCMM's performance management system, monitoring, and evaluation of their workers' job performance. The many determinants of job behaviour and performance render labour, or the ability to work, nebulous. This poses challenges in ascertaining the skills status quo, especially in light of the notion of broad skills. This challenge has serious implications for a developing country's skills development plans and policies, such as South Africa. One school of thought argues that there is a shortage of skills while another says there is an excess, with each blaming inappropriate worker behaviour on the situation they describe (Kaseke, 2011; Stokes, 2010; Faling, 2011). This is a classic example of this challenge. Further research in this regard is needed in order to distinguish between skills shortages and poor work ethic of employees. 


\section{AUTHOR INFORMATION}

Prakash Singh is a professor at the Nelson Mandela Metropolitan University in Port Elizabeth, South Africa. He is an NRF rated researcher and a Fulbright scholar. His niche research areas of publication are organizational behaviour and social psychology. Professor Singh is the author of Innovative Strategies to Develop Better Schools and co-author of Principal Leadership. He has also published widely in peer-reviewed journals and has presented numerous papers at international conferences. E-mail: Prakash.Singh@nmmu.ac.za (Corresponding author)

Thembinkosi Twalo is currently employed as a Chief Researcher who is on the doctoral internship program at the Human Sciences Research Council. He is studying for a PhD degree at the Nelson Mandela Metropolitan University in Port Elizabeth, South Africa. His present research focus is on job behaviour and performance. He has published several articles in peer reviewed journals and has presented papers at international conference. E-mail: ttwalo@hsrc.ac.za

\section{REFERENCES}

1. Almquist, E. M., Chafetz, J. S., Chance, B. J., \& Corder-Bolz, J. (1978). Sociology: Women, men, and society. Minnesota: West Publishing Company.

2. Badenhorst, J. (2012). In focus: Buffalo City is definitely a metro and is viable. Available from http://www.dispatch.co.za/in-focus-buffalo-city-is-definitely-a-metro-and-is-viable/

3. Becker, G. S. (1975). Human capital: A theoretical and empirical analysis with special reference to education. New York: National Bureau of Economic Research (NBER).

4. Benya Nqolase, Z. (2011). The effectiveness of poverty alleviation initiatives in Buffalo City Metropolitan Municipality. (Unpublished MA dissertation). Port Elizabeth: Nelson Mandela Metropolitan University.

5. Blackmore, J. (1997). The gendering of skill and vocationalism in twentieth-century Australian education. In A. H. Halsey, H. Lauder, P. Brown, \& A. S. Wells (Eds.), Education: Culture, economy and society. New York: Oxford University Press.

6. Bourdieu, P. (1977). Cultural reproduction and social reproduction. In A. H. Halsey, H. Lauder, P. Brown, \& A. S. Wells (Eds.), Power and ideology in education. New York: Oxford University Press.

7. Breytenbach, J. (2009). Restaurant accused of racism. Retrieved from http://www.iol.co.za/news/politics/restaurant-accused-of-racism-1.430732

8. Bryant, L. (2012). Functionalism and education 2012. Retrieved from http://www.historylearningsite.co.uk/functionalsim_education.htm

9. Buffalo City Metropolitan Municipality. (2011). KPA Achievement Report. Retrieved from http://www.buffalocity.gov.za/municipality/annual_report10-11/final/prt2_kpa_report.pdf

10. Buffalo City Metropolitan Municipality. (2012). Draft 2012/2013 Medium Term Revenue and Expenditure Framework (MTREF) Budget. Retrieved from www.buffalocity.gov.za/municipality/keydocs/mtref2012_13.pdf

11. Business Dictionary. (2013). Nonparametric method. Retrieved from http://www.businessdictionary.com/definition/nonparametric-method.html

12. Chansarn, S. (2010). Labor productivity growth, education, health and technological progress: A crosscountry analysis. Economic Analysis \& Policy, 40(2), 249-261.

13. Coetzer, P. (2009, November 26). Service delivery falls prey to political expediency: Minister to put a turnaround strategy on the table. Retrieved from http://www.servicepublication.co.za/index.php/magazine/other/175-service-delivery-falls-prey-to-politicalexpediency

14. Creswell, J. W., \& Plano-Clark, V. L. (2007). Designing and constructing mixed research methods. New Delhi: Sage.

15. Dalai Lama. (2013). 50 Dalai Lama quotes to enrich your life. Retrieved from http://quotesnsmiles.com/quotes/50-dalai-lama-quotes/

16. De Kock, R. (2012). Damning AG report on East Cape municipalities. Retrieved from http://www.peherald.com/news/article/7525 
17. Department of Cooperative Governance and Traditional Affairs (COGTA). (2010). Capacity building at municipalities. Retrieved from www.pmg.org.za/.../20100817-capacity-building-municipalities-nationaltreasury-dbsa-department-co

18. Faling, C. (2011). The service delivery dilemma: Skills shortage or poor work ethic. Skills Universe. Retrieved March 01, 2012 from http://www.skills-universe.com/profiles/blogs/the-service-deliverydilemma

19. Guerrero, L. (2005). Sociology and the study of social problems. Retrieved from www.sagepub.com/upmdata/4617_Leon_Guerrero_Chapter_1.pdf

20. Haralambos, M., \& Heald, R. (1985). Sociology: Themes and perspectives. London: Bell \& Hyman.

21. Ingbretsen, R. M. (2011). Develop your reputation capital. Retrieved from http://www.selfgrowth.com/articles/develop_your_reputation_capital.html

22. Investopedia. (2013). Nonparametric statistics. Retrieved from http://www.investopedia.com/terms/n/nonparametric-statistics.asp

23. Kaseke, L. L. (2011). Challenges facing the Limpopo Department of Public Works with regard to service delivery: A case of the core functions of the department. University of Limpopo (Turfloop Campus).

24. Local Government Municipal Structures Act No. 117 of 1998. Government Gazette: Cape Town. Retrieved from http://mfma.treasury.gov.za/MFMA/Legislation

25. Local Government Municipal Systems Act No. 32 of 2000. Government Gazette: Cape Town. Retrieved from http://mfma.treasury.gov.za/MFMA/Legislation

26. Loggi. (2009). Skills exodus sends BCM to the brink of collapse. Retrieved from http://iluvsa.blogspot.com/2009/03/skills-exodus-sends-bcm-to-brink-of.html

27. Mabindla, N. (2003). Buffalo City is the best in SA. Retrieved from http://www.buffalocity.gov.za/news2003/dec/dec8_vunawin.stm

28. Maudlen, B., Bentley, K., Dwyer, W. O., \& Houston, D. (2004). Secondary education and the underprepared workforce: is a poor work ethic being taught? Business Perspectives, 16(2). Retrieved from http://law-journals-books.vlex.com/vid/secondary-prepared-workforce-ethic-taught/61744104

29. Mawonga, T. A. (2012). A critical analysis of the applicability of the King III in the local government sphere - A case of the Buffalo City Metropolitan Municipality in the Eastern Cape from 2009-2011. (Unpublished Master of Public Administration Thesis). University of Fort Hare, Faculty of Management and Commerce.

30. McShane, S., \& Von Glinow, M. (2009). Organizational behavior: Emerging knowledge and practice for the real world. New York: McGraw-Hill.

31. Moore, J. W., \& Moore, B. M. (1982). Social problems. Englewood Cliffs, N.J: Prentice-Hall, Inc.

32. Mxengi, M. (2012). SAMWU wants mayor to resign. Retrieved from http://issuu.com/feveronline/docs/east_london_fever_28_sept_2012

33. My Market Research Methods. (2012). Types of data \& measurement scales: Nominal, ordinal, interval and ratio. Retrieved from http://www.mymarketresearchmethods.com/types-of-data-nominal-ordinalinterval-ratio/

34. Nini, A. (2012a). AG blames political leaders. Retrieved from http://www.dispatch.co.za/news/article/3190

35. Nini, A. (2012b). BCM's R1.4 bn audit disgrace. Retrieved from http://www.dispatch.co.za/news/article/2744

36. Nombembe, T. (2011). Municipalities' misuse of money rockets. Retrieved from http://www.fin24.com/Economy/Municipalities-misuse-of-money-rockets-20110630

37. Nombembe, T. (2012a). Consolidated general report on the audit outcomes of Local Government 2010-11. Retrieved from http://www.agsa.co.za/Reports\%20Documents/MFMA\%20consolidated.pdf

38. Nombembe, T. (2012b). General report on the audit outcomes of Local Government EASTERN CAPE 2011-12. Auditor-General. Pretoria.

39. Nombembe, T. (2013). Consolidated general report on the audit outcomes of Local Government 2011-12. Auditor-General. Pretoria.

40. Ratings Africa. (2011). Municipal Financial Stability Index 2011: Trends visible. Retrieved from http://www.ratingsafrika.com/opinions.htm

41. SALGA. (2011). Guideline document on the roles and responsibilities of councillors, political structures and officials. Retrieved from http://www.salga.org.za/pages/Knowledge--Hub/Guidelines-forMunicipalities 
42. Singh, P. (2011). SWEAT analysis to determine organisational effectiveness. In J. H. Westover (Ed.),

Examining job satisfaction: Causes, outcomes and comparative differences. Champaign, Illinois: Common Ground Publishing LLC.

43. Stokes, G. (2010). South Africa Inc laments skills shortage. Retrieved from http://www.fanews.co.za/article.asp?Front_Page_Features 25,Straight_Talk 1146,South_Africa_Inc_lame nts_skills_shortage 7443

44. Times Live. (2011). Major problems in Eastern Cape Education Department: Motshekga. Retrieved from http://www.timeslive.co.za/politics/2011/08/23/major-problems-in-eastern-cape-education-departmentmotshekga

45. Times Live. (2012). Reality check on services. Retrieved from http://www.timeslive.co.za/thetimes/2012/07/24/reality-check-on-services

46. Van Onselen, G. (2012). How cadre deployment has brought Buffalo City to its knees. Retrieved from http://inside-politics.org/2012/04/25/how-cadre-deployment-has-brought-buffalo-city-to-its-knees/

47. Westover, J. H. (2011). The relationship between job satisfaction and other important individual, organizational, and social outcomes. In J. H. Westover (Ed.), Examining job satisfaction: Causes, outcomes and comparative differences. Champaign, Illinois: Common Ground Publishing LLC. 
NOTES 